\title{
LAS COOPERATIVAS Y SU ACCIÓN SOBRE LA SOCIEDAD
}

\author{
POR \\ Alejandro MARTÍNEZ CHARTERINA ${ }^{1}$
}

\section{RESUMEN}

El Plan para una década cooperativa de la Alianza Cooperativa Internacional, aprobado tras la celebración del Año Internacional de las Cooperativas de Naciones Unidas, pone el acento del modelo de empresa cooperativa, que está resultando especialmente adecuado frente a la crisis actual, en la participación tanto en la propiedad de la empresa como en la toma de decisiones (gestión democrática), en la búsqueda de la sostenibilidad económica, social y medioambiental, y en la existencia de una identidad formada por los valores y principios cooperativos. El modelo cooperativo se centra en la persona y en la sociedad en que lleva a cabo su actividad.

Palabras clave: cooperativismo y sociedad, alianza cooperativa internacional y acción social, acción social cooperativa.

Claves Econlit: A130; P130; Z130

\section{COOPERATIVES AND ITS EFFECT ON SOCIETY}

\section{ABSTRACT}

The Blueprint for a cooperative decade of the International Cooperative Alliance, approved after celebrating the United Nations International Year of Cooperatives, places special emphasis on the cooperative business model. This is being particularly suitable to face the current crisis regarding participation in business ownership and decision-making (democratic management), the search for economic, social and environmental sustainability, and the existence of an identity consisting of cooperative values and principles. The

\footnotetext{
${ }^{1}$ Catedrático de la Universidad de Deusto. Director del Instituto de Estudios Cooperativos de la Facultad de Derecho. Dirección de correo electrónico: amartin@ deusto.es.
}

REVESCO No 117 - MONOGRÁFICO: Las sociedades cooperativas construyen un mundo mejor - ISSN: 1885-8031 - www.ucm.es/info/revesco

http://dx.doi.org/10.5209/rev_REVE.2015.v117.48144

Fecha de recepción: 12/12/2014

Fecha de aceptación: 17/12/2014 
cooperative model focuses on individuals and the society in which they perform their activities.

Keywords: cooperativism and society, international cooperative alliance and social action, cooperative social action.

\section{LA EMPRESA COOPERATIVA}

La Alianza Cooperativa Internacional define la cooperativa como "una asociación de personas que se han unido de forma voluntaria para satisfacer sus necesidades y aspiraciones económicas, sociales y culturales en común mediante una empresa de propiedad conjunta y de gestión democrática” (I.C.A., 1996: 17).

Esta definición de cooperativa que realiza la Alianza en su Congreso Centenario de Manchester en 1995 sigue las pautas de lo que se ha venido considerando una cooperativa, desde los orígenes del cooperativismo moderno, en su doble condición simultánea de asociación de personas y empresa económica que popularizó Georges Fauquet (1965: 39-40)². Al mismo tiempo introduce en la definición las notas más esenciales y distintivas de la cooperativa, a saber, la voluntariedad, la propiedad conjunta y la gestión democrática. Y, finalmente, pone de manifiesto que las pretensiones que acompañan a la cooperativa no son únicamente económicas, sino también sociales y culturales.

En efecto, la cooperativa es en origen un recurso para obtener de forma compartida la satisfacción de una necesidad común. Es una alternativa a las posibilidades o a la falta de posibilidades, y una aplicación más de la obtención de la "fuerza" mediante la "unión".

Así lo presenta Holyoake cuando en las primeras páginas de su Historia de los Pioneros de Rochdale, tan conocida, relata cómo los trabajadores de Manchester fracasan en su intento de obtener unos salarios más justos, a pesar de los buenos resultados de la industria textil de aquellos tiempos, y deciden mejorar sus condiciones de vida a través de la constitución de una cooperativa de consumo, la "Rochadale Society of Equitable Pioneers", la que consideramos el origen del cooperativismo moderno (Holyoake, 1989).

Merece la pena recordar la frase textual que emplea Georges Jacob Holyoake al referirse a la consecuencia del fracaso en la consecución de los salarios merecidos: "Entonces

\footnotetext{
${ }^{2}$ Según Aranzadi (1976: 210), la doble consideración se remonta a Mariano Mariani a principio del siglo XX. REVESCO No 117 - MONOGRÁFICO: Las sociedades cooperativas construyen un mundo mejor - ISSN: 1885-8031 - www.ucm.es/info/revesco
} 
algunos tejedores de Rochdale recordaron las ideas de Robert Owen. Los socialistas de aquella época, no obstante sus concepciones distintas, prestaron un gran servicio al hacer comprender a los obreros que tanto ellos como los patrones son esclavos de la organización comercial e industrial existente, y que si muchos obreros de hoy fueran patrones mañana procederían del mismo modo que los industriales, de quienes se quejan. Es el conjunto de circunstancias y el ambiente social lo que hay que modificar" (Holyoake, 1989: 10).

La cooperativa se preocupa por el ambiente social desde sus mismos orígenes. No es sólo el deseo de satisfacer una necesidad lo que anima a la cooperativa que, siendo asociación de personas, gestiona de forma democrática una empresa de propiedad conjunta de esas mismas personas que voluntariamente quieren formar parte de la misma, sino que, además tratan de modificar la sociedad en la que viven y las circunstancias no deseables de la misma. Nos dice hoy Ángel Petriella que en "una humanidad rica que fabrica pobres... no se trata de combatir la pobreza sino la perversa distribución de la riqueza” (Petriella, 2013: 114).

\section{EL MODELO DE EMPRESA COOPERATIVA}

En estos tiempos de crisis que seguimos padeciendo se ha llamado mucho la atención acerca de la resistencia de la cooperativa frente a la crisis, muy superior, comparativamente hablando, a la de las empresas capitalistas convencionales ${ }^{3}$.

En este sentido los Informes Birchall-Ketilson de 2009 y Birchall de 2013, realizados para la Organización Internacional del Trabajo, lo ponen de manifiesto. El primero, que se titula Resiliencia de las cooperativas en tiempos de crisis, para las cooperativas con carácter general, y el segundo, cuyo título es Resiliencia en tiempo de crisis: el poder de las cooperativas financieras, específicamente para éstas. Y la razón de esa resistencia y flexibilidad ante la crisis se cifra precisamente en el modelo de empresa de las cooperativas (Johnston Birchall y Lou Hammond Ketilson, 2009, y Johnston Birchall, 2013).

La empresa cooperativa, que pretende acomodar su actividad a unos valores de autoayuda, autorresponsabilidad, democracia, igualdad, equidad, solidaridad y ética, a través de la honestidad, transparencia, responsabilidad y vocación social de sus socios, se conduce mediante el cumplimiento de los conocidos principios cooperativos de:

\footnotetext{
${ }^{3}$ Trato este tema con más amplitud en el tema 2 "El sexto principio cooperativo" de la obra Gadea, Atxabal e Izquierdo (coordinadores), 2014 b:79 ss.
}

REVESCO No 117 - MONOGRÁFICO: Las sociedades cooperativas construyen un mundo mejor - ISSN: 1885-8031 - www.ucm.es/info/revesco 
- adhesión voluntaria y abierta,

- gestión democrática,

- participación económica de los socios,

- autonomía e independencia,

- educación, formación e información,

- cooperación entre cooperativas, e

- interés por la comunidad (I.C.A., 1996).

Estas características esenciales y específicas de las cooperativas nos permiten reflexionar acerca de los diferentes focos de interés que acompañan a las mismas.

En efecto, en primer lugar la cooperativa presenta una dimensión que atiende a la persona y su beneficio toda vez que se trata de una reunión de personas que comparten unos intereses y que pretenden realizarlos, pero inmediatamente esa realización se llevará a cabo entre todos y no de cualquier forma, sino a través de una empresa que pretende exhibir unos valores determinados y para ello va a actuar siguiendo unos principios ${ }^{4}$.

Y son los principios los que presentan el modelo de empresa que es una cooperativa. En esta empresa se participa de forma voluntaria como indica el primer principio, la puerta está abierta para entrar y para salir. La empresa se gestiona democráticamente, cada socio tiene un voto, con independencia de cualquier otra consideración, según el segundo principio.

El tercer principio indica que el capital de la cooperativa lo aportan los socios, si bien el interés que reciban en su caso será limitado, desvinculado del beneficio empresarial ${ }^{5}$. El beneficio, en la medida en que se reparta entre los socios, se distribuirá en proporción a sus operaciones con la cooperativa y, en ningún caso, en función del capital aportado.

El cuarto principio posiciona la autonomía de las cooperativas frente a cualquier pretensión de control externo, control que debe ser democrático por parte de los socios en cualquier caso.

\footnotetext{
${ }^{4}$ La Declaración sobre la Identidad Cooperativa indica que los principios "son pautas mediante las cuales las cooperativas ponen en práctica sus valores" (I.C.A., 1996: 17).

${ }^{5}$ El capital como factor de producción recibe como compensación el interés, que resulta una retribución fija. La única retribución variable es el beneficio empresarial, la diferencia entre ingresos y costes, que corresponde al empresario. En la cooperativa se separa la retribución del capital y de la actividad empresarial aunque ambas aportaciones al proceso productivo confluyan en las mismas personas.
}

REVESCO No 117 - MONOGRÁFICO: Las sociedades cooperativas construyen un mundo mejor - ISSN: 1885-8031 - www.ucm.es/info/revesco 
La conocida como regla de oro del cooperativismo, el quinto principio de educación, obliga a atender la educación de carácter general y la formación de carácter profesional a socios y sus empleados para que avancen en su propio crecimiento intelectual y en el ejercicio de su trabajo. Al mismo tiempo propone la información de la naturaleza y beneficios de la cooperación a la sociedad, especialmente a los jóvenes y líderes de opinión. Y en este principio se empieza a observar una dimensión del cooperativismo de mayor alcance, que mira a la sociedad para trasladarle los beneficios de la cooperación, lo que también sucederá con los últimos principios cooperativos.

\section{LA COOPERACIÓN ENTRE COOPERATIVAS}

Los cinco principios cooperativos que estamos considerando en los párrafos precedentes provienen de los orígenes del cooperativismo moderno, es decir, de los Estatutos de la Cooperativa de Rochdale de 1844, las enmiendas de los Estatutos realizadas en 1845, y acuerdos varios de Asambleas posteriores. En cambio los principios sexto y séptimo provienen de modificaciones posteriores de los principios realizadas por la Alianza Cooperativa Internacional en el Congreso de Viena de 1966, el primero de ellos, y en el Congreso Centenario de Manchester de 1995, el último (Martínez Charterina, 1996: 213 ss).

Considerando, en primer lugar, el principio de cooperación entre cooperativas, sexto en el orden de la Declaración de la Alianza, es preciso señalar que si bien es cierto que no se recoge como tal principio hasta el XXIII Congreso de la A.C.I. de Viena, en 1966, desde mediados del siglo XIX las cooperativas, primero inglesas y después continentales, habían ido creando un movimiento cooperativo nacional a través de sus Federaciones y Confederaciones, para llegar en 1895 a constituir la Alianza Cooperativa Internacional (Martínez Charterina, 2013: 187-188).

Por otro lado, desde finales del siglo XIX fue creciendo la dimensión de las empresas con las que las cooperativas tenían que confrontarse en el mercado, llegando a ser algunas de ellas primero empresas internacionales y después, sobre todo tras la segunda guerra mundial, multinacionales. Al mismo tiempo se estaba poniendo de manifiesto dentro del cooperativismo el conflicto de intereses entre las cooperativas de productores, principalmente agrícolas, y las de consumidores, toda vez que las primeras pretendían obtener unos precios altos y las segundas bajos.

REVESCO No 117 - MONOGRÁFICO: Las sociedades cooperativas construyen un mundo mejor - ISSN: 1885-8031 - www.ucm.es/info/revesco 
No es de extrañar que se presentara el informe de Thorsten Odhe, titulado "Integración económica y desarrollo cooperativo" al Congreso de la Alianza de 1963, celebrado en Bournemouth (Reino Unido), y que en el siguiente Congreso, el de Viena en 1966, se aprobara el principio de cooperación entre cooperativas.

Este principio considera que las cooperativas deben colaborar entre si a todos los niveles. Con ello refuerzan el movimiento cooperativo.

Y de este modo queda bien definido que el movimiento federativo que culmina en la Alianza Cooperativa Internacional tiene una función política y representativa, mientras que el principio de intercooperación facilita objetivos económicos y de competencia a las cooperativas.

Visto así se puede pensar en un proceso de reacción y de adaptación a las circunstancias del mercado. Pero el principio busca, además, la culminación de un proceso más profundo e inacabado, un proceso de solidaridad que trasciende el espacio de cada cooperativa y se extiende al conjunto. De nuevo, aparece la misión transformadora de la sociedad que acompaña a la cooperativa ${ }^{6}$.

\section{EL PRINCIPIO DE INTERÉS POR LA COMUNIDAD}

Se trata del séptimo de los principios cooperativos instaurado en el Congreso Centenario de la Alianza de 1995.

Aunque las cooperativas existen principalmente para el beneficio de sus socios, como éstos están unidos a un espacio geográfico, las cooperativas no pueden quedar al margen de las comunidades de sus socios. Así lo expresa el Informe que acompaña a la Declaración sobre la identidad cooperativa (ICA, 1996: 65).

Este principio aparece también vinculado a los deseos que los pioneros de Rochdale expresaban entre sus objetivos y planes en los primitivos Estatutos, en los que además de distribuir los artículos para la vida corriente en un almacén, la cooperativa de consumidores que se pone en marcha, se proponen construir viviendas, fabricar bienes para facilitar el trabajo a los socios desempleados, cultivar tierras con la misma finalidad... y "Tan pronto

\footnotetext{
${ }^{6}$ Se puede considerar el principio integrador como respuesta al reto del medio, pero también como conclusión de un proceso inacabado (Martínez Charterina, 1990: $11 \mathrm{ss}$ ).
}

REVESCO No 117 - MONOGRÁFICO: Las sociedades cooperativas construyen un mundo mejor - ISSN: 1885-8031 - www.ucm.es/info/revesco 
sea posible, esta sociedad procederá a la organización de las fuerzas de la producción, distribución, educación y gobierno...” (Laws and objects of the Rochdale Society..., 1884: 3; y Martínez Charterina, 2013: 186ss.).

Y ello conduce necesariamente a una responsabilidad de la cooperativa en lo que se refiere al desarrollo económico, social y medioambiental.

"Desde los valores y principios de su identidad, especialmente los valores de responsabilidad social y de vocación social a que son llamados los socios, y el principio séptimo de interés por la comunidad que dirige la actividad cooperativizada al desarrollo sostenible de la misma, las cooperativas asumen la responsabilidad social empresarial por su misma naturaleza” (Martínez Charterina, 2014 a: 61).

Dante Cracogna reflexiona sobre el sentido y ámbito de este principio afirmando que las cooperativas responden a las necesidades de sus socios cuando lo hacen de forma coherente con el desarrollo de sus comunidades, entendido ese desarrollo como sostenible, es decir, en armonía con el medio ambiente y en beneficio también de las futuras generaciones. Además la comunidad de referencia no es únicamente la comunidad local, sino también la internacional, "ya que el desarrollo local no puede lograrse sin preservarse la sostenibilidad mundial o, lo que es peor, a costa de ella".

La sostenibilidad presenta diversas formas y aunque se trate de dar preferencia a la sostenibilidad económica, el mantenimiento y desarrollo de la propia empresa en el tiempo, "sin sostenibilidad social, la sostenibilidad económica carece de sentido y finalidad desde el punto de vista cooperativo", y ambas, sostenibilidad económica y social, "dependen de la sostenibilidad del medio ambiente, que permite existir y sobrevivir a los otros dos tipos de sostenibilidad" (Cracogna, 2014: 16).

\section{LA ALIANZA COOPERATIVA INTERNACIONAL Y SUS OBJETIVOS}

La Alianza Cooperativa Internacional, hoy jurídicamente una Asociación internacional sin ánimo de lucro regida por la legislación belga, "es una red mundial... que ejerce las funciones de representante a nivel mundial de organizaciones cooperativas de toda índole"7.

\footnotetext{
${ }^{7}$ Artículo 4 de los Estatutos vigentes de la A.C.I. (2013). REVESCO No 117 - MONOGRÁFICO: Las sociedades cooperativas construyen un mundo mejor - ISSN: 1885-8031 - www.ucm.es/info/revesco
} 
Su Reglamento define los objetivos de la Alianza: “... reúne, representa y sirve a organizaciones cooperativas del mundo entero. La A.C.I. es la guardiana de los valores y principios cooperativos. Propugna el modelo empresarial de las cooperativas... persigue los siguientes fines:

a) fomentar el movimiento cooperativo internacional...

b) promover y proteger los valores y principios cooperativos;

c) facilitar el desarrollo de relaciones ... entre sus organizaciones miembros;

d) fomentar el desarrollo sostenible de la persona y favorecer el progreso económico y social de los pueblos contribuyendo así a la paz y seguridad mundiales;

e) promover la igualdad entre hombres y mujeres en todas las tomas de decisiones y actividades en el marco del movimiento cooperativo." 8

Con estas finalidades se ponen de relieve las ideas de unidad y universalidad del movimiento cooperativo, la salvaguarda de la identidad cooperativa, valores y principios, así como la existencia de unas aspiraciones de influencia en la sociedad, a juicio de Paul Lambert las "aspiraciones de conquista”, que conforman la esencia de la cooperación: “... queriendo... servir a sus miembros y a la colectividad entera, la cooperación tiende a conquistar y transformar la organización económica y social del mundo” ( Lambert, 1970: 272).

Y, aunque nos hemos fijado mucho más en el papel de la Alianza en cuanto custodia de los principios y los valores que caracterizan y diferencian a las cooperativas, las aspiraciones de lograr un mundo mejor a través de las cooperativas están presentes en la Alianza Cooperativa Internacional desde su creación. Desde la identidad cooperativa no se puede promocionar a la persona sin considerar la sociedad, el conjunto de todas las personas dentro y fuera de la cooperativa (Gómez, 1989: 101ss).

Y en ese contexto la Alianza traza líneas de actuación referidas al desarrollo de los pueblos, la educación universal, la satisfacción de las necesidades elementales, la vivienda, la salud, la protección al consumidor, el medio ambiente, la igualdad de género, la juventud y la

\footnotetext{
${ }^{8}$ Artículo 1 del Reglamento de la Alianza Cooperativa Internacional, adoptado por la Asamblea General de 11 de abril de 2013, que en la expresión de los fines de la Alianza reproduce los objetivos que anteriormente recogía el artículo 2 de su Estatuto (aprobado por la Asamblea General en 2008 y revisado por el mismo órgano en 2009).
}

REVESCO No 117 - MONOGRÁFICO: Las sociedades cooperativas construyen un mundo mejor - ISSN: 1885-8031 - $\underline{\text { www.ucm.es/info/revesco }}$ 
infancia, así como la búsqueda de la paz, que conforma el estado natural en el que la cooperativa puede llevar a cabo su actividad 9 .

Con estas proyecciones sociales del cooperativismo se justifican plenamente los enlaces políticos que aparecen, con cierta frecuencia, como el programa de Charles Gide sobre la república cooperativa, o la existencia del Partido Cooperativo Británico, el Partido Nacional Cooperativista de México, y la República Cooperativa de Guyana, o el papel que se reserva a las cooperativas en los planteamientos más globales y actuales, como el que hace Christian Felber en su obra La economía del bien común (Martínez Charterina, 2013: 190 ss).

\section{UNA CONSIDERACIÓN SOBRE LAS ACCIONES DE CONQUISTA DE LA} ALIANZA

Al igual que otras organizaciones internacionales, la Alianza Cooperativa Internacional se ha planteado qué pueden hacer las cooperativas de cara al desarrollo de los pueblos, y, muy especialmente desde el final de la segunda guerra mundial, y, consciente del papel que pueden llevar a cabo, ha impulsado al desarrollo de los países a través de las cooperativas, así como a la ayuda al desarrollo como parte de la acción cooperativa de colaboración, muy especialmente mediante la asistencia técnica (Gómez, 1989:127ss).

Uno de los pilares más importantes en los procesos de desarrollo es precisamente la educación de las personas que participan en el mismo, o, puesto en sentido contrario, la falta de educación es un elemento especialmente retardatario para el desarrollo ${ }^{10}$.

El cuidado de las cooperativas por la educación se remonta a los orígenes del cooperativismo y en ningún momento se ha dejado de atender en un sentido creciente. La educación, además de facilitar la formación de los socios y dirigentes para el desarrollo profesional de las cooperativas, y de informar a todos las personas de los beneficios de la cooperación, constituye el recurso mediante el cual los cooperativistas son capaces de entender y aceptar las acciones de las cooperativas que miran a la participación y empoderamiento de todas esas mismas personas para gestionar su empresa democráticamente, que buscan el fortalecimiento de la cooperativa a largo plazo renunciando al beneficio a corto plazo, que van más allá de sí mismas y de sus familias para atender a su entorno y, en última

\footnotetext{
${ }^{9}$ En este sentido me expresaba al prologar la obra de Laura Gómez, 1989: 9.

10 Entre los indicadores del subdesarrollo siempre aparece la falta de formación como uno de los más importantes (Martínez Charterina, 2011: 306).
}

REVESCO No 117 - MONOGRÁFICO: Las sociedades cooperativas construyen un mundo mejor - ISSN: 1885-8031 - www.ucm.es/info/revesco 
instancia, defender objetivos de transformación de la sociedad hacia una nueva sociedad más justa con las personas, sostenible para las futuras generaciones y conservadora del medio natural.

La Alianza no ha dejado de preocuparse por la educación, facilitando e impulsando programas educativos, y a través de sus propias publicaciones, entre las que destaca la Revista de la Cooperación Internacional (Gómez, 1998: 180ss).

El cooperativismo nació a partir de una preocupación fundamental por la mejora de las condiciones de vida de los trabajadores, como hemos mencionado anteriormente al referirnos al nacimiento de la cooperativa de Rochdale. La Alianza Cooperativa Internacional ha hecho suya desde su origen esa preocupación y ha impulsado el cuidado de dichas condiciones de vida ampliando las necesidades básicas a otros aspectos más cualificados pero importantes en la vida de las personas como la vivienda digna, el cuidado de la salud, el consumerismo o atención y formación en materia de consumo, el turismo social, y, en estos tiempos más recientes, conscientes de su importancia, la atención y cuidado del medio ambiente (Gómez, 1998: 209 ss).

En este sentido las cooperativas han desarrollado en muchas partes del mundo la vivienda cooperativa, las cooperativas médicas y de aseguramiento de la salud, las actividades económicas vinculadas al turismo, y todos los aspectos relacionados con la responsabilidad empresarial corporativa en lo relativo a la sostenibilidad y al cuidado del medio ambiente.

$\mathrm{Y}$, finalmente, aunque no por ello menos importante, ha de considerarse el trabajo incesante de la Alianza en favor de la igualdad de género, de los jóvenes y de la paz.

El trabajo de la Alianza sobre las mujeres ha sido incesante desde el nacimiento de las Ligas de mujeres cooperativistas que se remontan a 1883 en Gran Bretaña (Gómez, 1998: 246 ss).

En los tiempos más recientes puede citarse el Mensaje de la Alianza Cooperativa Internacional del año 2010, titulado "Las cooperativas favorecen el empoderamiento de las mujeres”, en el que se recuerda cómo las cooperativas proporcionan ventajas tanto a las mujeres socias como a las empleadas de cara a mejorar su nivel de vida, contribuyendo " $a$ mejorar la situación económica, social y cultural de las mujeres por medio de la promoción de la igualdad...”, y cómo las cooperativas atienden a cada uno de los cinco componentes del REVESCO No 117 - MONOGRÁFICO: Las sociedades cooperativas construyen un mundo mejor - ISSN: 1885-8031 - www.ucm.es/info/revesco 
empoderamiento, a saber, sentimiento de autoestima, capacidad para elegir y ser elegida, acceso a recursos y oportunidades, derecho al control de sus vidas, y capacidad para influir en el cambio social ${ }^{11}$.

Y, del mismo modo, en la Declaración del Comité Mundial de Género de la Alianza Cooperativa Internacional en el Día Internacional de la Mujer del presente año, se recuerda que "Nuestros principios y valores nos instan a promover un cambio de paradigma en las relaciones de género, declarando y promoviendo que sólo lograremos progreso para todos, si las mujeres contribuyen en igualdad de condiciones que los hombres a sus sociedades y se benefician por igual de las mismas $" 12$.

Los jóvenes constituyen, por su parte, un foco de interés para la Alianza Cooperativa Internacional como se puso de manifiesto en la redacción del principio de educación que hizo el Congreso Centenario de la ACI en Manchester, en 1995, al decir que las cooperativas “...informan al gran público, especialmente a los jóvenes y a los líderes de opinión, de la naturaleza y beneficios de la cooperación” (I.C.A., 1996: 19).

El hecho de que no se contemple hasta la última redacción de los principios específicamente a los jóvenes no quiere decir, en modo alguno, que no se les haya dado importancia anteriormente. A fin de cuentas, nos recuerda Laura Gómez que de los veintiocho fundadores de la cooperativa de Rochdale veintisiete tenían menos de treinta años, y que desde los años treinta del pasado siglo ya existía un Comité Internacional de Jóvenes Cooperativistas (Gómez, 1998: 277-278).

Lo cierto es que ese interés por los jóvenes se ha ido intensificando desde el Congreso de la ACI de Hamburgo de 1984, que formuló una resolución al respecto (Rhodes and Mavrogiannis, 1995: 163), hasta nuestros días en que un representante de los jóvenes forma parte de la Junta que gestiona la Alianza desde 2003.

Y dedicó el Mensaje en la celebración del Día Internacional de las Cooperativas de 2011, el año previo al Año Internacional de las Cooperativas, a los jóvenes, a los que el

\footnotetext{
${ }^{11}$ Mensaje de la Alianza Cooperativa Internacional, en el $88^{\circ}$ Día Internacional de las Cooperativas de la ACI, el 3 de julio de 2010.

12 Comité Mundial de Género de la Alianza Cooperativa Internacional, Declaración Día Internacional de la Mujer 2014, "Igualdad para las mujeres, progreso para todos".
}

REVESCO No 117 - MONOGRÁFICO: Las sociedades cooperativas construyen un mundo mejor - ISSN: 1885-8031 - www.ucm.es/info/revesco 
cooperativismo tiene mucho que ofrecer y de los que puede recibir también mucho, y a los que consideraba entonces el futuro de la empresa cooperativa ${ }^{13}$.

Por fin la paz, que ha constituido un objetivo de la Alianza desde antes de su propia creación, que ha inspirado la neutralidad de la misma a lo largo de su existencia, en un contexto de múltiples y graves conflictos internacionales, y que ha orientado muchas acciones y pronunciamientos en favor de la misma (Gómez, 1998: 293 ss).

Por ello, también, la Alianza se propone entre sus objetivos "fomentar el desarrollo sostenible de la persona y favorecer el progreso económico y social de los pueblos contribuyendo así a la paz y seguridad mundiales" ${ }^{\prime 4}$.

\section{EL AÑO INTERNACIONAL DE LAS COOPERATIVAS Y EL PLAN PARA UNA DÉCADA COOPERATIVA}

La Asamblea General de las Naciones Unidas proclamó el año 2012 como Año Internacional de las Cooperativas justamente con el lema "Las cooperativas ayudan a construir un mundo mejor", fijándose en la contribución de éstas al desarrollo económico y social, en especial en la reducción de la pobreza, la creación de empleo y la integración social (www.un.org/es/events/coopysyear).

Fueron múltiples las actividades que se desarrollaron en todo el mundo con ocasión de este año 2012, y se avanzó notablemente en la difusión de las aportaciones de las cooperativas a la sociedad, generándose una mayor conciencia de la importancia y el sentido de esas realizaciones.

Ese tiempo de reflexión y celebración dio lugar también al establecimiento del Plan para una década cooperativa, redactado por Cliff Mills y Will Davies bajo la orientación del Grupo de Trabajo de Planificación de la Alianza Cooperativa Internacional, aprobado por la Asamblea General de la Alianza, y que se propone para el horizonte de 2020 que el modelo empresarial cooperativo se reconozca como "líder de sostenibilidad económica, social y medioambiental”, sea preferido y crezca más que otros modelos (A.C.I., 2013:3).

\footnotetext{
13 Mensaje de la Alianza Cooperativa Internacional en la celebración del $89^{\circ}$ Día Internacional de las Cooperativas de ACI (2011), La juventud, el futuro de las empresas cooperativas.

${ }^{14}$ En el artículo 1, letra d, del Reglamento de la alianza Cooperativa Internacional (adoptado por la Asamblea General de 11 de abril de 2013).
}

REVESCO No 117 - MONOGRÁFICO: Las sociedades cooperativas construyen un mundo mejor - ISSN: 1885-8031 - $\underline{\text { www.ucm.es/info/revesco }}$ 
En este Plan se trata de potenciar la participación como elemento característico de las cooperativas ofreciendo a los jóvenes esta alternativa, de insistir en la sostenibilidad, connatural e intrínseca a las mismas, en los diversos aspectos económicos, muy relacionados con las oportunidades de desarrollo, sociales, para enfrentar los problemas el individualismo y la desigualdad, y medioambientales, para atender los deseos de cambio de rendimientos financieros por conservación de la naturaleza.

También se siente la necesidad de conferir visibilidad a las cooperativas y sus aportaciones, dando valor en el mensaje a la identidad cooperativa de forma que no quede duda de la importancia que los valores y principios tienen en la conducta de estas empresas. Y se insiste en el valor del principio de educación y de sus frutos.

Por fin se plantea la conveniencia de profundizar en la consecución de unos marcos jurídicos adecuados para facilitar el crecimiento del modelo de la empresa cooperativa, sin pretender con ello la búsqueda de ventajas particulares frente a otros modelos, pero sin renunciar a las mejores posibilidades de desarrollarse. Y la necesidad de encontrar fórmulas que permitan la obtención de capital a largo plazo, para lo que las posibilidades de los socios resultan insuficientes en la actualidad, sin que ello obstaculice la gestión democrática por parte de los socios así como toda la compatibilidad con la identidad cooperativa.

\section{CONCLUSIÓN}

Aunque, seguramente a lo largo del tiempo, se ha dado más relieve a la consideración de la cooperativa como un proyecto de realización personal de autoayuda, en el que cada socio junto con los demás que forman la cooperativa lleva adelante una empresa económica participando democráticamente en su gestión, la identidad cooperativa ha facilitado, por medio de la capacidad de relación y el sentido de pertenencia de los cooperativistas, la formación de un movimiento cooperativo, que ha impulsado la acción cooperativa, más allá de los propios objetivos empresariales vinculados a la satisfacción de las necesidades de las personas que forman la entidad, a la atención a la sociedad en la que desarrollan su vida.

A partir de esta consideración no es difícil proyectar el interés cooperativo por la sostenibilidad de sus acciones, en lo económico, social y medioambiental, así como la toma

REVESCO No 117 - MONOGRÁFICO: Las sociedades cooperativas construyen un mundo mejor - ISSN: 1885-8031 - www.ucm.es/info/revesco 
de posición del cooperativismo frente a una globalización que no impulsa al desarrollo de los países pobres y que conduce cada vez a una mayor desigualdad en el mundo ${ }^{15}$.

El cooperativismo, en síntesis, debe ser un ejemplo "de que otro modelo de organización social es posible, basado no en el lucro, en el interés y la optimización de los bienes de consumo, sino en la solidaridad y la igualdad de oportunidades...”, aplicable a toda la humanidad (Petriella, 2013:118).

\section{BIBLIOGRAFÍA}

A.C.I. (2013) Plan para una década cooperativa. www.aciamericas.coop/IMG/pdf/ica_blueprint_es.pdf

ARANZADI, D. (1976) Cooperativismo industrial como sistema, empresa y experiencia. Bilbao: Universidad de Deusto.

BIRCHALL, J. (2013) Resilience in a downturn: The power of financial cooperatives. Geneva: ILO.

BIRCHALL, J. y KETILSON, L. H. (2009) Resilience of the Cooperative Business Model in Time of Crisis. Geneva: ILO.

CRACOGNA, D. (2014) Orientación sobre el séptimo principio. ica.coop/sites/default/files/attachments/DRAFT\%20Guidance\%20Notes\%20P3,\%20P5,\% 20P7\%20Spanish\%202014-02-11.pdf, pp.16-19.

FAUQUET, G. (1965) Le secteur coopératif. Oeuvres. Paris: Publications de l'Institut des Etudes Coopératives, pp. 21-127.

FELBER, C. (2012) La economía del bien común. Barcelona: Deusto - Grupo Planeta.

GÓMEZ, L. (1998) La Alianza Cooperativa Internacional y su desarrollo como institución y en especial como instrumento transformador de la sociedad. Vitoria-Gasteiz: Consejo Superior de Cooperativas de Euskadi.

HOLYOAKE, G. J. (1989) Historia de los Pioneros de Rochdale. Buenos Aires: Intercoop.

I.C.A. (1996) Declaración de la Alianza Cooperativa Internacional sobre la identidad cooperativa. Los principios cooperativos. Vitoria-Gasteiz: Consejo Superior de Cooperativas de Euskadi.

\footnotetext{
${ }^{15}$ El Informe de Oxfam de 20 de enero de 2014, titulado Gobernar para las élites. Secuestro democrático y desigualdad económica, señala como la nota más característica el crecimiento de la desigualdad económica en la mayor parte de los países del mundo, no sólo en los países en vías de desarrollo, sino también en los desarrollados.
}

REVESCO No 117 - MONOGRÁFICO: Las sociedades cooperativas construyen un mundo mejor - ISSN: 1885-8031 - www.ucm.es/info/revesco 
I.C.A., Comité Mundial de Género: Declaración Día Internacional de la Mujer 2014 "Igualdad para las mujeres: progreso para todos". ica.coop/sites/default/files/media_items/ICA\%20Gender\%20Committee\%20Women\%27s \%20Day\%20statement\%202014\%20-\%20ES.pdf

I.C.A. Estatutos. ica.coop/sites/default/files/attachments/ICA\%20Articles\%20-\%20updated\%202013\%20$\% 20$ Spanish.pdf

I.C.A. Reglamento. ica.coop/sites/default/files/attachments/ICA\%20Bylaws\%20-\%20updated\%202013\%20$\% 20$ Spanish.pdf

Informe Oxfam (2014) Gobernar para las élites. Secuestro democrático y desigualdad económica. $\quad$ http://www.oxfamintermon.org/sites/default/files/documentos/files/bpworking-for-few-political-capture-economic-inequality-200114-es.pdf

LAMBRT, P. (1970) La doctrina cooperativa. $3^{\text {a }}$ edición. Buenos Aires: Intercoop.

Laws and objects of the Rochdale Society of Equitable Pioneers: enrolled according to the Acts, $10^{\text {th }}$, George IV, and $4^{\text {th }}$ and $5^{\text {th }}$, William IV. (1844). Rochdale: Printed by Jesse Hall.

MARTÍNEZ CHARTERINA, A. (1990) Análisis de la integración cooperativa. Bilbao: Universidad de Deusto.

MARTÍNEZ CHARTERINA, A. (1996) La cooperativa como empresa y los principios cooperativos tras el congreso centenario de la A.C.I. de Manchester. En Obra colectiva. Evolución del escenario económico. Bilbao, Universidad de Deusto, pp. 207-226.

MARTÍNEZ CHARTERINA, A. (2011) Introducción a la economía. Madrid: Dykinson.

MARTÍNEZ CHARTERINA, A. (2013) Cooperativismo y economía del bien común. Boletín de la Asociación Internacional de Derecho Cooperativo, $\mathrm{n}^{\circ}$ 47, pp. 185-198.

MARTÍNEZ CHARTERINA, A. (2014 a) Cooperativas y responsabilidad social empresarial. Deusto Estudios Cooperativos, $\mathrm{n}^{\circ}$ 4, pp. 49-62.

MARTÍNEZ CHARTERINA, A. (2014 b) El sexto principio cooperativo. En GADEA, Enrique, ATXABAL, Alberto, IZQUIERDO, Marta (coordinadores) Las cooperativas como alternativa económica: Una visión de México y España. Madrid: Dykinson, pp. 7994.

MENSAJE DE LA ALIANZA COOPERATIVA INTERNACIONAL 2010: Las cooperativas favorecen el empoderamiento de las mujeres. www.aciamericas.coop/IMG/pdf/2010-idces-2.pdf

REVESCO No 117 - MONOGRÁFICO: Las sociedades cooperativas construyen un mundo mejor - ISSN: 1885-8031 - www.ucm.es/info/revesco 
MENSAJE DE LA ALIANZA COOPERATIVA INTERNACIONAL 2011: La juventud, el futuro de las empresas cooperativas.

www.aciamericas.coop/IMG/pdf/diainternacional2011.pdf

PETRIELLA, A. (2013) Lo cooperativo como herramienta de transformación social. Revista Idelcoop, $\mathrm{n}^{\circ} 211$, pp. 111-130.

RODHES, R. y MAVROGIANNIS, D. (1995) Thematic Guide to ICA Congresses 18951995. Geneva: ICA. 